\title{
A rapid annealing technique for efficient perovskite solar cells fabricated in air condition under high humidity
}

Jie Xu ${ }^{a}$, Ziyang $\mathrm{Hu}^{\mathrm{a}, *}$, Xianyu Jia ${ }^{\mathrm{a}}$, Like Huang ${ }^{\mathrm{b}}$, Xiaokun Huang ${ }^{\mathrm{a}}$, Liming Wang ${ }^{\mathrm{a}}$, Peng Wang

a, Houcheng Zhang ${ }^{\text {a }}$ Jing Zhang ${ }^{\text {a }}$, Jianjun Zhang ${ }^{\mathrm{b}}$, Yuejin Zhu ${ }^{\mathrm{a}, *}$

${ }^{a}$ Department of Microelectronic Science and Engineering, Ningbo Collabrative Innovation Center of Nonlinear Hazard System of Ocean and Atmosphere, Ningbo University, Ningbo 315211, China.

${ }^{\mathrm{b}}$ College of Electronic Information and Optical Engineering, Nankai University, Tianjin, 300071, China

Abstract: A rapid annealing technique for fabricating perovskite materials via microwave radiation in air condition is presented. A planar-heterojunction perovskite device via microwave radiation within 6 min exhibits an efficiency of $10.29 \%$, compared to $11.08 \%$ for a 90 minute heating-annealed device in inert atmosphere, which is higher than that (8.04\%) of a heating-annealed device in air condition under high humidity ( 60\%). We believe that the microwave annealing technique provides a fast and less energy-intensive process for fabricating ideal perovskite active layers for high performance solar cells.

Keywords: Perovskite solar cell, Microwave radiation, Organometal halide perovskite, Annealing; Thin film photovoltaics

\section{Introduction}

*Email address: huziyang@nbu.edu.cn, zhuyuejin@ nbu.edu.cn 
Solid-state organic-inorganic lead halide perovskite solar cells have recently been the spotlight of intense study due to their solution processable, low cost materials and high performance. ${ }^{1-6}$ Since 2009, a liquid dye-sensitized solar cell(DSC) using organic-inorganic lead halide perovskites as sensitizers initially reached a power conversion efficiency (PCE) of 3.8\% [1]. In 2012, PCEs of solid perovskite photovoltaic devices combining with excellent hole transport layers were increased up to $10 \%$ [2-3]. After one year, the PCE soared to $15.4 \%$ when the perovskite film was deposited by physical vapour process [4]. The recent records of perovskite solar cells were $\sim 20 \%$, which suggests a great potential for widely commercial applications [5-6]. At the beginning, the device structure of the perovskite solar cells was inherited from the traditional DCS using the mesoporous metal oxides such as $\mathrm{TiO}_{2}$ as scaffold [2]. However, the perovskite solar cells using a mesoporous network of insulating $\mathrm{Al}_{2} \mathrm{O}_{3}$ nanoparticles also yielded a high PCE [3], suggesting that electron transfer is facilitated entirely through the perovskite material itself rather than the mesoporous $\mathrm{TiO}_{2}$ network. Since that, planar-heterojunction $(\mathrm{PH})$ architectures excluding mesoporous layers have been employed for the simplified fabrication procedures [4-5]. Meanwhile, the long lifetime and diffusion length of carriers within perovskite crystalline consolidate the feasibility of using the $\mathrm{PH}$ structure [7-8]. For a typically device fabrication, a blend solution including methyl ammonium iodide $\left(\mathrm{CH}_{3} \mathrm{NH}_{3} \mathrm{I}\right)$ and a lead halide salt $\left(\mathrm{PbCl}_{2}\right.$ or $\left.\mathrm{PbI}_{2}\right)$ dissolved in DMF (N,N-dimethylformamide) or (dimethylsulfoxide) DMSO is deposited onto the substrate through spin coating or dip coating. The heating process is necessary to evaporate organic solvent within the film and to ensure the crystallization of the perovskite precursor, especially for the mixed-halide perovskites $\mathrm{CH}_{3} \mathrm{NH}_{3} \mathrm{PbI}_{3-\mathrm{x}} \mathrm{Cl}_{\mathrm{x}}$ materials [7-9]. For mesoporous DSCs dye molecules are adsorbed onto scaffold surface at room temperature, while in 
$\mathrm{PH}$ perovskite solar cells the solution processable materials are required to develop into crystallization by thermal annealing [10-12]. In order to obtain high device performance, the annealing treatment always endure the duration of about 30 to 120 min to achieve optimal crystallization [5-6,13-18]. The annealing treatment was further carried out in gradual or stepped heating model [19-22]. For the large-scale manufacture of perovskite solar cells, a time consuming process is contradicted to low cost fabrication. Also, it is relative difficulty to control the whole heating process under ambient conditions for a long time [23-24]. Thermal annealing is traditionally implemented through thermal conduction methods, such as the use of hotplates or ovens. During such processes, it is very hard to make full use of the heating energy. To replace this process, a noncontact and rapid treatment approach to annealing has been investigated using near-infrared radiation [25-26] or microwave irradiation [27-37]. A lot of work has been carried out for inorganic and organic syntheses under microwave treatment. Since the microwave heating is directly occurred between the materials and the electric field, it is an efficient and energy saving way of reaction. A few studies have focused on the behaviour of conjugated polymers under microwave irradiation in order to enhance the efficiency of polymer solar cells [27-30]. Also, microwave heating of $\mathrm{TiO}_{2}$ layer on different substrates for DSCs was reported [31-35].

In this contribution, we first presented an alternative method of annealing perovskite films for only 6 min while a high PCE was still achieved. The freshly deposited perovskite film was exposed to microwave radiation using commercial microwave oven. A PH perovskite solar cell exhibited a PCE of $10.29 \%$ in air condition under high humidity of $60 \%$, compared to $11.08 \%$ for a 90-minute heating-annealed device in inert atmosphere. 


\section{Experimental section}

\section{1 Materials}

If there is no special statement, all materials were purchased from Sigma-Aldrich and Acros. Methyl ammonium iodide $\left(\mathrm{CH}_{3} \mathrm{NH}_{3} \mathrm{I}\right)$ was synthesized by the available process as reported in literature. First, $18.7 \mathrm{ml}(0.15 \mathrm{~mol})$ methylamine (33 wt.\% in absolute ethanol) and $19.8 \mathrm{ml}(0.15$ mol) hydroiodic acid (57 wt.\% in water) at a 1:1 equimolar ratio were stirred in an ice bath for $2 \mathrm{~h}$. Then the precipitate was collected by evaporating at $50{ }^{\circ} \mathrm{C}$ for $2 \mathrm{~h}$. Finally, a white powder was received by washing with diethyl ether three times and then drying at $60{ }^{\circ} \mathrm{C}$ in a vacuum oven for $24 \mathrm{~h}$. The $\mathrm{TiO}_{2}$ blocking layer was synthesized from a sol-gel method in air ambient. $0.675 \mathrm{~mL}$ of titanium(IV) isopropoxide was added to $17.75 \mathrm{~mL}$ of isopropanol and $0.25 \mathrm{~g}$ of diethanolamine; 17.5 $\mu \mathrm{L}$ of deionized water were added before stirring for $5 \mathrm{~min}$ at room temperature, then the sol was left to age for half an hour before using.

\section{2 Device fabrication}

FTO coated glass substrates were thoroughly cleaned and treated by ozone-ultraviolet for 15 min. A $40 \mathrm{~nm}$ thick $\mathrm{TiO}_{2}$ compact $\left(\mathrm{c}-\mathrm{TiO}_{2}\right)$ layer was spin-coated at $4000 \mathrm{rpm}$ for $25 \mathrm{~s}$ on the substrates using the sol-gel solution. The c-TiO ${ }_{2}$ layer was then heated at $450{ }^{\circ} \mathrm{C}$ for $30 \mathrm{~min}$. Before using, the substrates were dipped in a aqueous solution of $\mathrm{TiCl}_{4}(0.04 \mathrm{M})$ at $70{ }^{\circ} \mathrm{C}$ for 30 min, then rinsed with deionized water and dried at $120{ }^{\circ} \mathrm{C}$ for $15 \mathrm{~min}$. To deposit the perovskite layer, a 1:3 ratio of $\mathrm{PbCl}_{2} / \mathrm{CH}_{3} \mathrm{NH}_{3} \mathrm{I}(0.8 \mathrm{M}$ and $2.4 \mathrm{M})$ was mixed in DMF. The solution was spin-coated on the $\mathrm{FTO} / \mathrm{c}_{-} \mathrm{TiO}_{2}$ substrates at $2000 \mathrm{rpm}$ for $50 \mathrm{~s}$. The deposited precursor films were irradiated under air condition with a commercial microwave at $2.45 \mathrm{GHz}$, and a varied power output from 80 to $640 \mathrm{~W}$ in a multimode cavity. If there is no special statement, the microwave 
radiation was preliminarily performed under air condition with humidity of $30-40 \%$. A hole transport layer solution was spin-coated on treated perovskite films at $3000 \mathrm{rpm}$ for $30 \mathrm{~s}$, in which $1 \mathrm{~mL}$ spiro-OMeTAD/chlorobenzene $\left(72.3 \mathrm{mgmL}^{-1}\right)$ solution was employed with addition of 18 $\mu \mathrm{L} \mathrm{Li-TFSI/acetonitrile} \mathrm{(520} \mathrm{mgmL}^{-1}$ ), and $29 \mu \mathrm{L}$ 4-tert-butylpyridine. Lastly, a silver layer was thermally evaporated under a pressure of $4 \times 10^{-4} \mathrm{~Pa}$. The completed devices have a configuration glass/FTO/c- $\mathrm{TiO}_{2} /$ perovskite/spiro-MeOTAD/Ag, which consists of $\sim 450 \mathrm{~nm}$ thick FTO electrode, $\sim 40 \mathrm{~nm}$ of $\mathrm{TiO}_{2}, \sim 400 \mathrm{~nm}$ of perovskite, $\sim 400 \mathrm{~nm}$ of spiro-MeOTAD, and $\sim 120 \mathrm{~nm}$ of Ag. The details about device fabrication please refer to our previous reports [21-22].

\section{3 Device Characterization}

The UV-Vis absorption spectra of the perovskite films were measured by a VARIAN Cary 5000 UV-Vis-NIR spectrophotometer. The X-ray diffraction (XRD) pattern were obtained from perovskite films deposited on the $\mathrm{FTO} / \mathrm{c}-\mathrm{TiO}_{2}$ substrates using a Bruker D8 Advance diffractmeter equipped with a LynxEye XE detector using $\mathrm{Cu}-\mathrm{K} \alpha$ radiation $(\lambda=1.54050 \AA)$. The top view images and thicknesses of the deposited perovskite films were confirmed by a Hitachi SU-70 scanning electron microscope (SEM). For temperature measurements, a thermographic camera (VARIOSCAN 3022) was used. The current density-voltage measurements were conducted under simulated AM 1.5G sunlight of $100 \mathrm{mWcm}^{-2}$ using an AM 1.5G type filter (Newport, 81904, USA). The light intensity was adjusted by using a standard Si cell. $J-V$ curves were obtained by applying an external bias to the cell, and measurements were recorded with a Keithley model 2400 digital source meter at room temperature in ambient air. The scan directions of the forward and reverse voltage scans are from $-0.2 \mathrm{~V}$ to $1.2 \mathrm{~V}$ and from $1.2 \mathrm{~V}$ to $-0.2 \mathrm{~V}$, respectively. The scan rate was $0.03 \mathrm{Vs}^{-1}$ with a volatage step of $0.015 \mathrm{~V}$. The effective area of the cell was $0.07 \mathrm{~cm}^{2}$. 


\section{Results and discussion}

In the multimode of microwave irradiation process, the intensity of the electric field is almost the same in whole chamber. Theoretically, the position of the sample can be randomly placed at the microwave oven. As a primary experiment, irradiation conditions including alternatively varied microwave irradiation power and time were preliminarily optimized. The current density-voltage $(J-V)$ characteristics of perovskite solar cells under different irradiation conditions are presented in Table 1 . The corresponding $J-V$ curves refer to Fig. 1S. The highest performance devices with PCEs over 9\% can be achieved by alternatively increased exposure duration and reduced the power. We tried to anneal the perovskite films with the maximum power for the shortest time to induce crystallization. However, the FTO coated glass substrates easily cracked because of the sharp temperature rise under the high power. Considering under low power condition more than $10 \mathrm{~min}$ is required to annealing the samples, so we chose a mild power of 320 $\mathrm{W}$ to further optimize the device performance under different radiation times. Additionally, the metal $\mathrm{Ag}$ is a good absorber of microwave, thus the microwave annealing process was performed before the Ag electrode was deposited. Actually, we have annealed the completed device with glass/FTO/c- $\mathrm{TiO}_{2} /$ perovskite/spiro-MeOTAD/Ag using microwave radiation, but the experiment was failed.

Fig. 1 displays the $J-V$ characteristics of the devices annealed by microwave radiation for various times at $320 \mathrm{~W}$. The performance was increased and then reduced upon increasing the radiation time. After the irradiation for 6 min, the maximal PCE of $\sim 10.81 \%$, a short circuit current density $\left(J_{s c}\right)$ of $20.44 \mathrm{mAcm}^{-2}$, an open-circuit voltage $\left(V_{o c}\right)$ of $0.90 \mathrm{~V}$, and a fill factor $(\mathrm{FF})$ 
of $58.8 \%$ are achieved. The $J_{s c}$ and FF were improved along with the duration of microwave irradiation by 6 min and then reduced, while the $V_{o c}$ s were almost the same. Fig. 2 further provides a summary of the overall device performance with respect to the radiation time. The device with microwave radiation for 6 min shows a narrow distribution of performance parameters, which indicates the optimal radiation time.

In order to address the effect of microwave irradiation to the perovskite films, the temperature of the different substrates was directly detected by digital thermometer during the process of microwave irradiation at $320 \mathrm{~W}$. The varied temperature as a function of microwave irradiation time for eight different substrates including glass, glass/FTO, glass/c- $\mathrm{TiO}_{2}$, glass/perovskite, glass/c- $\mathrm{TiO}_{2} /$ perovskite, $\quad$ glass/FTO/c- $\mathrm{TiO}_{2}, \quad$ glass/FTO/perovskite, $\quad$ and glass/FTO/c-TiO $2 /$ perovskite were measured as shown in Fig. 3(a). The temperatures increased gradually within initial 10 min of microwave irradiation, and the temperatures of all the substrates tend to saturate. The temperatures of the glass, glass/c- $\mathrm{TiO}_{2}$, glass/perovskite, and glass/c- $\mathrm{TiO}_{2} /$ perovskite which exclude FTO layer show a linear and slow rise along with the increased time, indicating that the amount of energy absorbed by these materials is very low. Even these samples were microwave irradiated for $10 \mathrm{~min}$, only $\sim 50{ }^{\circ} \mathrm{C}$ was obtained. In contrast, the temperatures of glass/FTO, glass/FTO/c-TiO $2, \quad$ glass/FTO/perovskite, and glass/FTO/c- $\mathrm{TiO}_{2} /$ perovskite substrates which include $\mathrm{FTO}$ layer increased rapidly upon increasing the radiation time. We infer that FTO absorbs microwave radiation far more readily, causing it to rapidly heat under microwave irradiation. Combined with the relative transparency of the $\mathrm{c}-\mathrm{TiO}_{2}$ film to microwave radiation, the fast heated FTO layer allows for rapid and indirect annealing of the perovskite materials. 
We should point out that once the polarized molecules (DMF used as solvent in our experiments) are residual in perovskite films, the microwave irradiation causes them to oscillate, which then dissipates this energy into heat the perovskite film. However, the samples consist of glass/c- $\mathrm{TiO}_{2} /$ perovskite and glass/perovskite did not show the sharp rising of the temperature. We suppose that the DMF solvent was almost vapored when the precursor solution was spin coated with high rate. The dominating heating source is from the heated FTO not the energy dissipation by the polarized molecules. This is different with the previous report that used the microwave-assisted solvent vapour annealing [28]. Additionally, we note that the measured temperature for the optimized device efficiency was similar to those reported previously for other thermal annealing methods $\left(\sim 90-100{ }^{\circ} \mathrm{C}\right)[5,10,16-17]$. These results suggested that the FTO substrate was well absorbed microwave and the whole sample was warmed through the heated FTO layer. Furthermore, the temperature of the glass/FTO substrate with $\mathrm{c}-\mathrm{TiO}_{2}$ or c- $\mathrm{TiO}_{2} /$ perovskite was a little higher than that of the glass/FTO, which indicates effectively accelerate the radiation of the heat from the surface of FTO. Previously, Curet et al reported that microwave irradiation did not affect the transparent conductive oxide while the temperature of the active layer increased dramatically [27]. The single mode irradiation and the setting position of the sample may lead to the different result for microwave absorption. According to the above discussion, the annealing process and heat transfer process are schematic shown in Fig. 3(b).

Fig. 4 shows the evolutions of the colour when the perovskite films were exposed to microwave irradiation for various times. As can be seen, the heated perovskite films undergo the non-uniform change in colour. The presented different colours of the perovskite film radiated for 3 min indicated the heated temperature of different zones. The four corners of the sample show the 
organic-yellow, suggesting the low-temperature zones. When the perovskite film was exposed for 6 min, the whole zone of the sample shows the well-distributed black. In Fig. 4(f), the light yellow zones were assigned to the formed $\mathrm{PbI}_{2}$ due to the overheating. The yellow zone also suggests where the decomposition of the perovskite film first begins. This unique pattern may be a result of the heating of microwave irradiation. However, in the case of Fig. 4(d), the most homogeneously coloured sample was obtained by the optimizing time, and the device performance shows the well distributed parameters as presented in Fig. 2.

The rapid processing technique for perovskite solar cells tempts us to compare with the devices fabricated by heating-annealing in inert atmosphere and air condition. Because the humidity is the key factor that affects the perovskite film formation and resultant device performance. Due to the rapid heating treatment, this may alleviates the detrimental influence of the humidity during the developed crystallization of perovskite. The critical humidity for fabricating perovskite film in air condition is 50\% [36-38]. To clarify that the rapid heating will substantially alleviate this influence of humidity, we have conducted the experiment under the humidity of $60 \%$. As expected, the perovskite solar cell fabricated under humidity of $60 \%$ exhibits a poor photovoltaic performance with a $V_{o c}$ of 0.88V, a $\mathrm{J}_{s c}$ of $19.44 \mathrm{mAcm}^{-2}$, an FF of 0.47, and a PCE of 8.04\% (Fig. 5), which is comparable to the previously reported values [37-38]. However, the perovskite solar cell fabricated by microwave radiation show a promising PCE of $10.29 \%$ with a $V_{o c}$ of $0.92 \mathrm{~V}$, a $J_{s c}$ of $19.98 \mathrm{mAcm}^{-2}$, an FF of 0.56 . As a comparison, a perovskite solar cell heating-annealing in inert atmosphere with the identical device configuration was also fabricated, which exhibited a PCE of $11.08 \%$ with a $V_{o c}$ of $0.92 \mathrm{~V}$, a $J_{s c}$ of $20.07 \mathrm{mAcm}^{-2}$, an $\mathrm{FF}$ of 0.60 . The corresponding incident photo-current conversion efficiency (IPCE)spectra are shown in Fig. 5(b). 
Since surface coverage and crystallinity of perovskite film can significantly affect the resulting device performance because the defects in the crystals and the void within the films create severe charge recombination and shorting to deteriorate charge transport and collection. Further characterization was performed to evaluate the influence of the different annealing process. As shown in Fig. 6 (a, b, c), the colour of the resultant perovskite film exhibits gray when it was fabricated by heating-annealing in air condition (HAAC), while the colour of the resultant perovskite films exhibit black when they were fabricated by microwave radiation in air condition (MRAC) and heating-annealing in inert atmosphere (HAIA). This indicates that the humidity in the atmosphere severely affects the nucleation and crystallization of perovskite during the long process of film evolution. In Fig. 6 (d, e, f), the scanning electron microscopy (SEM) images show the distinct microstructures and morphologies of the corresponding perovskite films. As can be seen, the coverage and homogeneity of the perovskite films are remarkably improved when the perovskite films were fabricated by MRAC and HAIA. The morphology of the MRAC and HAIA treated perovskite films show a larger crystalline domain. This difference may originate from the fast ejected gases, acting like inert-protection atmosphere, can reduce the permeability of oxygen/moisture to enhance the film stability. Therefore, water molecules do not affect the quality of perovskite films under high humidity during the heating process. This uniformly covered perovskite surface also played a positive role in improving interfacial contacts and thus enhancing photovoltaic properties from the MRAC and HAIA based cells.

The UV-vis absorption and X-ray diffraction (XRD) spectra shown in Fig. 7 also confirm this observed trend. The MRAC perovskite film shows strong and efficient absorption characteristics featuring clear coverage between $300 \mathrm{~nm}$ and $800 \mathrm{~nm}$, which is similar to the HAIA perovskite 
film. However, a drastic decreased absorption was observed in the HAAC perovskite film, indicating the severe decomposition of perovskite structure during perovskite phase formation in ambient process. The increased absorption can be attributed to the improved surface coverage and crystallinity in the perovskite films. The increasing band-edge absorption around $750 \mathrm{~nm}$ also suggests the increased film crystallinity, demonstrating that the MRAC perovskite film present more crystallinity compared to the HAIA perovskite film. The XRD patterns of all the perovskite films show the tetragonal phase at room temperature. As shown in $\underline{\text { Fig. } \mathbf{7 ( b )}}$, the characteristic peaks at $14.2^{\circ}, 28.5^{\circ}, 43.3^{\circ}$ and $59.0^{\circ}$ are correspondingly assigned to the (110), (220), (330) and (440) crystal planes, respectively $[1,3]$. However, the intensity of each diffraction peak of the MRAC perovskite film is stronger than those of the HAIA and HAAC perovskite films, which indicates the improved crystallinity of the prepared perovskite films. As previous reported, the rapid formation of the perovskite films by hot-casting methods result in the large-area crystal grain and increased crystallinity [39]. In the XRD spectra, a peak at $12.6^{\circ}$, which is the characteristic peak for $\mathrm{PbI}_{2}$, was clearly observed for the HAAC perovskite film. The (001) diffraction peak of $\mathrm{PbI}_{2}$ may derive from the degraded perovskite structures during the formation of perovskite phase in the ambient conditions during the long heating process. However, we did not find any XRD signal in the MRAC perovskite film. We speculate that the rapid microwave radiation facilitate perovskite recrystallization during the annealing process and alleviate the influence of the humidity. Nevertheless, we find that high-quality perovskite films can be obtained when it is radiated under high humidity. This result shows that the performance of a MRAC perovskite under high humidity condition is comparable to those fabricated in the glove box. This signifies that it is feasible to use the microwave radiation technique for rapid formation perovskite films in the 
future.

\section{Conclusions}

In conclusion, a high efficiently perovskite solar cell has been demonstrated by using the microwave radiation technique within a few minutes under high humidity. With this faster and less energy-intensive processing method, crystallographic analysis has shown a more preferentially oriented structure, enabling less damage on photoactive layer of the cell than that of thermal annealing method. These results demonstrate the feasibility of fabricating large-area perovskite devices under ambient condition in the future. Furthermore, using the microwave irradiation, the efficient power supply became possible, giving way for continuous processing under mild conditions without any undesirable contact of heating substrate.

\section{Acknowledgements}

This work was supported by the National Science Foundation of China (Grant Nos. 11304170, 11374168, and 51302137). The authors would like to thank the sponsor by K.C. Wong Magna Fund in Ningbo University and the China Scholarship Council (CSC).

\section{References}

[1] A. Kojima, K. Teshima, Y. Shirai and T. Miyasaka, J. Am. Chem. Soc. 131 (2009) 6050.

[2] H.S. Kim, C.R. Lee, J.H. Im, K.B. Lee, T. Moehl, A. Marchioro, S.J. Moon, R.H. Baker, J.H. Yum, J.E. Moser, M. Grätzel and N.G. Parl, Sci. Rep. 2 (2012) 591.

[3] M.M. Lee, J. Teuscher, T. Miyasaka, T.N. Murakami and H.J. Snaith, Science 338 (2012) 643. 
[4] M. Liu, M.B. Johnston and H.J. Snaith, Nature, 501 (2013) 395.

[5] H. Zhou, Q. Chen, G. Li, S. Luo, T. Song, H.S. Duan, Z. Hong, J. You, Y. Liu, Y. Yang, Science, 345 (2014) 542.

[6] W.S. Yang, J.H. Noh, N.J. Jeon, Y.C. Kim, S. Ryu, J. Seo, S.I. Seok, Science 348 (2015) 1234.

[7] S.D. Stranks, G.E. Eperon, G. Grancini, C. Menelaou, M.J.P. Alcocer, T. Leijtens, L.M. Herz, A. Petrozza, H.J. Snaith, Science 342 (2013) 341.

[8] D. Shi, V. Adinolfi, R. Comin, M. Yuan, E. Alarousu, A. Buin, Y. Chen, S. Hoogland, A. Rothenberger, K. Katsiev, Y. Losovyj, X. Zhang, P.A. Dowben, O.F. Mohammed, E.H. Sargent, O.M. Bakr, Science 347 (2015) 519.

[9] Q. Chen, H. Zhou, Y. Fang, A.Z. Stieg, T.B. Song, H.H. Wang, X. Xu, Y. Liu, S. Lu, J. You, P. Sun, J. McKay, M.S. Goorsky and Y. Yang, Nat. Commun. 6 (2015) 7269.

[10] G.E. Eperon, V.M. Burlakov, P. Docampo, A. Goriely, H.J. Snaith, Adv. Funct. Mater. 24 (2014) 1517.

[11] F.X. Xie, D. Zhang, H. Su, X. Ren, K.S. Wong, M. Gratzel, W.C.H. Choy, ACS nano 9 (2015) 639.

[12] X. Wang, X. Li, G Tang, L. Zhao, W. Zhang, T. Jiu, J. Fang, Org. Electron. 24 (2015) 205.

[13] W. Qiu, M. Buffière, G Brammertz, U.W. Paetzold, L. Froyen, P. Heremans, D. Cheyns, Org. Electron. 26 (2015) 30.

[14] A.T. Barrows, A.J. Pearson, C.K. Kwak, A.D.F. Dunbar, A.R. Buckley and D.G. Lidzey, Energy Environ. Sci. 7 (2014) 2944.

[15] C. Bi, Y. Shao, Y. Yuan, Z. Xiao, C. Wang, Y. Gao and J. Huang, J. Mater. Chem. A 2 (2014) 18508. 
[16] M. Saliba, K.W. Tan, H. Sai, D.T. Moore, T. Scott, W. Zhang, L. Estroff, A.U. Wiesner, H.J. Snaith, J. Phys. Chem. C 118 (2014) 17171.

[17] A. Dualeh, N. Tétreault, T. Moehl, P. Gao, M.K. Nazeeruddin, M. Grätzel, Adv. Funct. Mater. 24 (2014) 3250.

[18] A.E. Williams, P.J. Holliman, M.J. Carnie, M.L. Davies, D.A. Worsley and T.M. Watson, J. Mater. Chem. A 2 (2014) 19338.

[19] R. Kang, J.E. Kim, J.S. Yeo, S. Lee, Y.J. Jeon and D.Y. Kim, J. Phys. Chem. C 118 (2014) 26513.

[20] H.L. Hsu, C.P. Chen, J.Y. Chang, Y.Y. Yu and Y.K. Shen, Nanoscale 6 (2014) 10281.

[21] L. Huang, Z. Hu, J. Xu, K. Zhang, J. Zhang, Y. Zhu, Sol. Energy Mater. Sol. Cell 141 (2015) 377.

[22] L. Huang, Z. Hu, G. Yue, J. Liu, X. Cui, J. Zhang and Y. Zhu, Phys. Chem. Chem. Phys. 17 (2015) 22015.

[23] A. Binek, F.C. Hanusch, P. Docampo, and T. Bein, J. Phys. Chem. Lett. 6 (2015) 1249.

[24] B. Conings, J. Drijkoningen, N. Gauquelin, A. Babayigit, J. D’Haen, L. D’Olieslaeger, A. Ethirajan, J. Verbeeck, J. Manca, E. Mosconi, F.D. Angelis, and H.G. Boyen, Adv. Energy Mater. 15 (2015) 1500477

[25] J. Troughton, C. Charbonneau, M.J. Carnie, M.L. Davies, D.A. Worsley and T.M. Watson, J. Mater. Chem. A 3 (2015) 9123.

[26] M.J. Carnie, C. Charbonneau, P.R.F. Barnes, M.L. Davies, I. Mabbett, T.M. Watson, B.C. O'Regan and D.A. Worsley, J. Mater. Chem. A 1 (2013) 2225.

[27] C.J. Ko, Y.K. Lin, and F.C. Chen, Adv. Mater. 19 (2007) 3520. 
[28] B. Jung, K. Kim and W. Kim, J. Mater. Chem. A 2 (2014) 15175.

[29] H. Flügge, H. Schmidt, T. Riedl, S. Schmale, T. Rabe, J. Fahlbusch, M. Danilov, H. Spieker, J. Schöbel, and W. Kowalsky, Appl. Phys. Lett. 97 (2010) 123306.

[30] O. Yoshikawa, T. Sonobe, T. Sagawa, and S. Yoshikawa, Appl. Phys. Lett. 94 (2009) 083301.

[31] P.S. Shen, C.M. Tseng, T.C. Kuo, C.K. Shih, M.H. Li, P. Chen, Sol. Energy 120 (2015) 345.

[32] S. Uchida, M. Tomiha, N. Masaki, A. Miyazawa, H. Takizawa, Sol. Energy Mater. Sol. Cell $81(2004) 135$.

[33] P.S. Shen, Y.C. Tai, P. Chen, Y.C. Wu, J. Power Sources 247 (2014) 444.

[34] K.P.S. Parmar, E. Ramasamy, J. Lee, J.S. Lee, Chem. Commun. 47 (2011) 8572.

[35] H.E. Wang, L.X. Zheng, C.P. Liu, Y.K. Liu, C.Y. Luan, H. Cheng, Y.Y. Li, L. Martinu, J.A. Zapien, I. Bello, J. Phys. Chem. C. 115 (2011) 10419.

[36] J. You, Y. Yang(Michael), Z. Hong, T.B. Song, L. Meng, Y. Liu, C. Jiang, H. Zhou, W.H. Chang, G. Li, and Y. Yang, Appl. Phys. Lett. 105 (2014) 183902.

[37] Z. Yang, C.C. Chueh, F. Zuo, J.H. Kim, P.W. Liang, and A.K.Y. Jen, Adv. Energy Mater. 13 (2015) 1500328.

[38] S. Wozny, M. Yang, A.M. Nardes, C.C. Mercado, S. Ferrere, M.O. Reese, W. Zhou, and K. Zhu, Chem. Mater. 27 (2015) 4814.

[39] W. Nie, H. Tsai, R. Asadpour, J.C. Blancon, A.J. Neukirch, G. Gupta, J.J. Crochet, M. Chhowalla, S. Tretiak, M.A. Alam, H.L. Wang, A.D. Mohite, Science 347 (2015) 522.

\section{Table caption}

Table $1 J-V$ characteristics of perovskite solar cells after preliminary microwave irradiation for 
various times.

Figure captions

Fig. 1 Representative $J-V$ characteristics of perovskite solar cells with microwave radiation at 320 W for various times.

Fig. 2 Effects of the microwave radiation times under $320 \mathrm{~W}$ on the values of $V_{o c}(a), J_{s c}(b), F F$ $\underline{(c), \text { and } P C E(d)}$.

Fig. 3 (a) Temperature measurements of various substrates as a function of microwave $\underline{\text { irradiation time, (b) schematic shows heat transfer direction in glass/FTO/c-TiO } 2 \text { /perovskite }}$ sample.

Fig. 4 The colour evolution of perovskite samples for various radiation times, (a) $3 \mathrm{~min}$, (b) $4 \mathrm{~min}$, (c) $5 \mathrm{~min}$, (d) $6 \mathrm{~min}$, (e) $8 \mathrm{~min}$, (f) $10 \mathrm{~min}$. The size of sample is $2.5 \times 2.5 \mathrm{~cm}$.

Fig. 5 (a) $\mathrm{J}-\mathrm{V}$ data for devices fabricated by heating-annealing in inert atmosphere (HAIA), heating-annealing in air condition (HAAC) and microwave radiation in air condition (MRAC), (b) the corresponding incident photo-current conversion efficiency (IPCE)spectra.

Fig. 6 Photographs and top view SEM images of perovskite films fabricated by microwave $\underline{\text { radiation in air condition }(M R A C)(a, d), \text { heating-annealing in air condition }(H A A C)(b, e), \text { and }}$ heating-annealing in inert atmosphere (HAIA) $(c, f)$. The size of photographs is $2.5 \times 2.5 \mathrm{~cm}$. Fig. 7 (a) UV-vis absorption spectra and (b) X-ray diffraction spectra of perovskite films prepared by microwave radiation in air condition (MRAC), heating-annealing in air condition (HAAC), and heating-annealing in inert atmosphere (HAIA). 
Figure 1

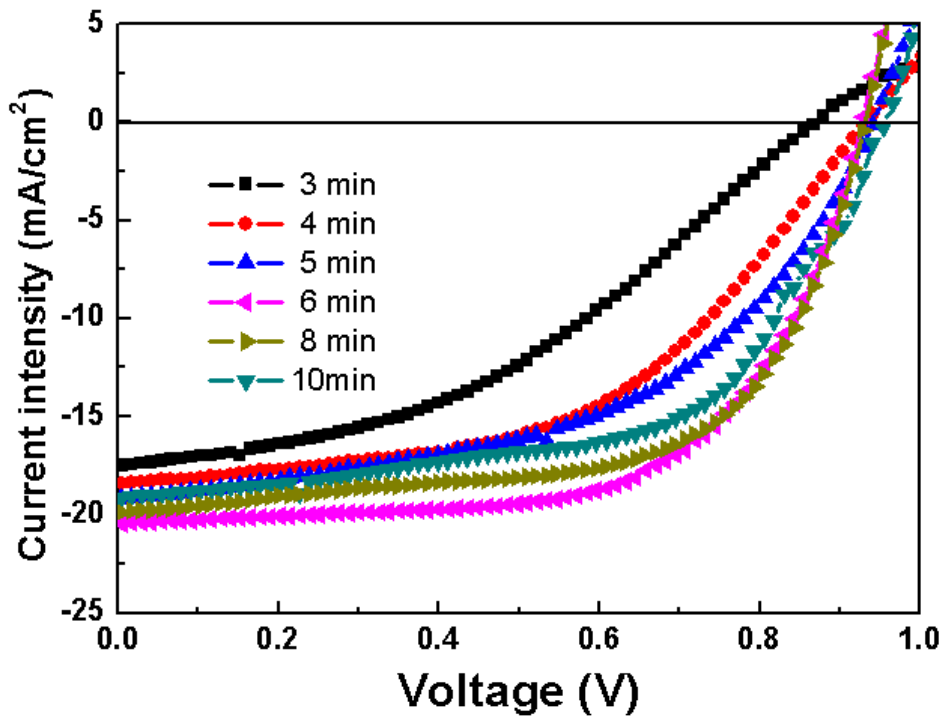




\section{Figure 2}

(a)

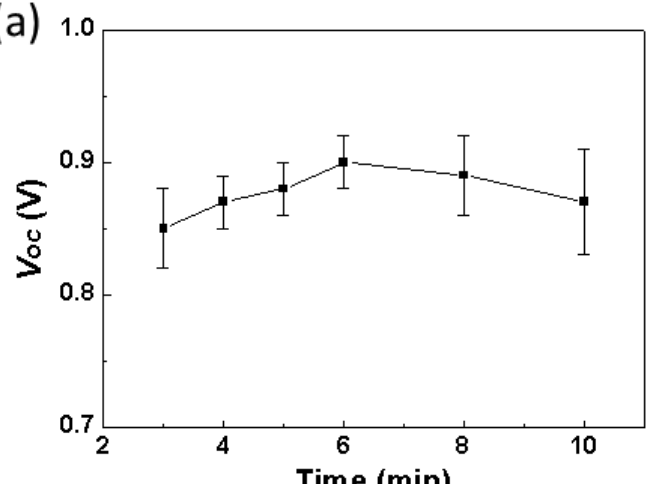

(c)

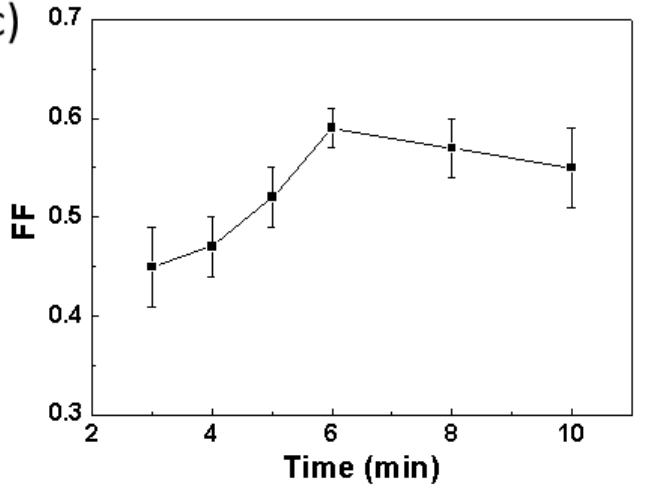

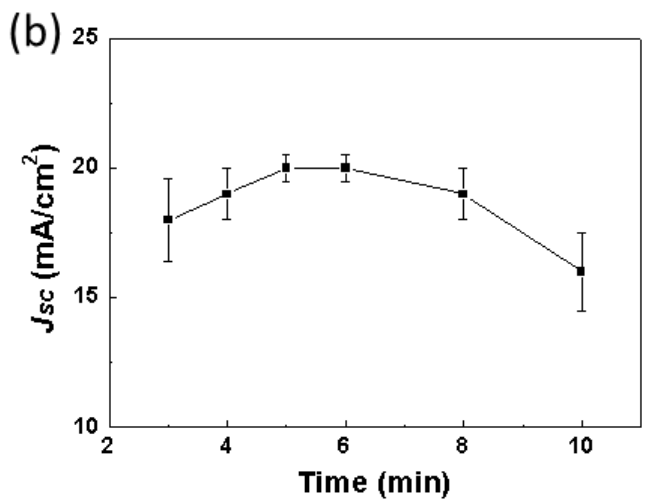

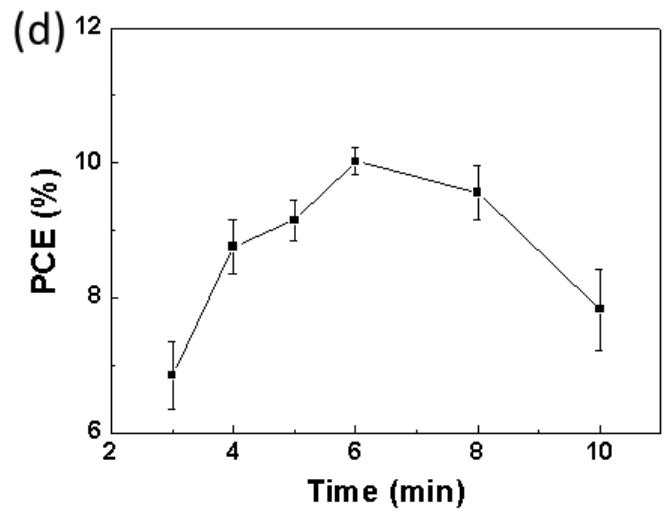


Figure 3

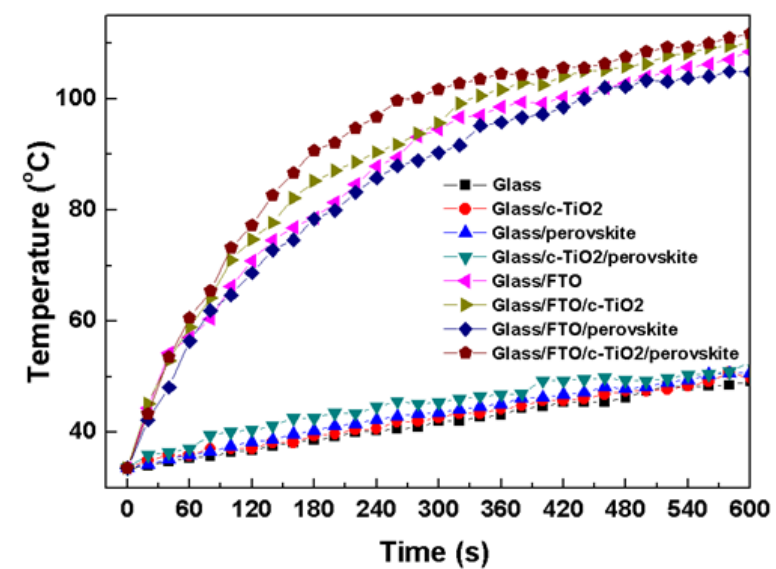

(a)

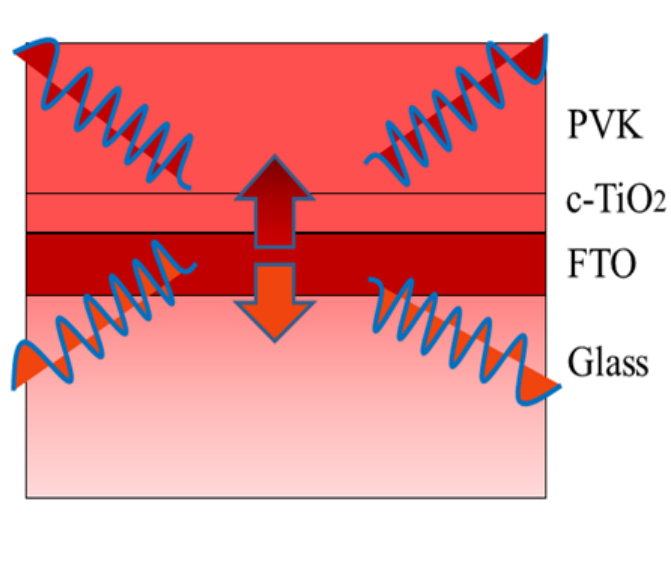

(b) 
Figure 4

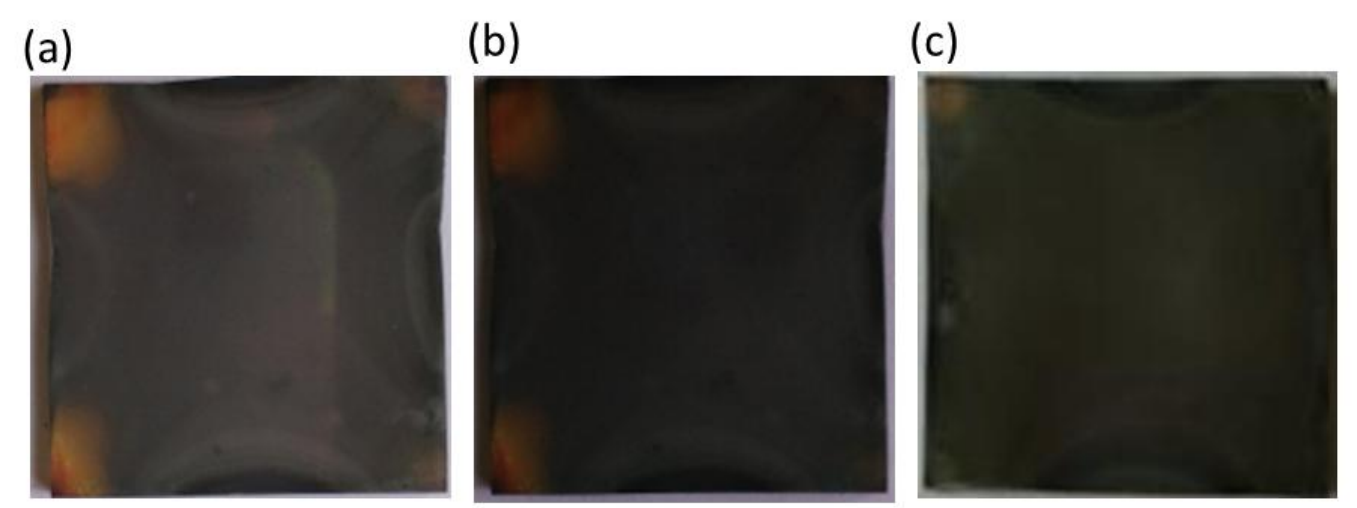

(d)

(e)

(f)

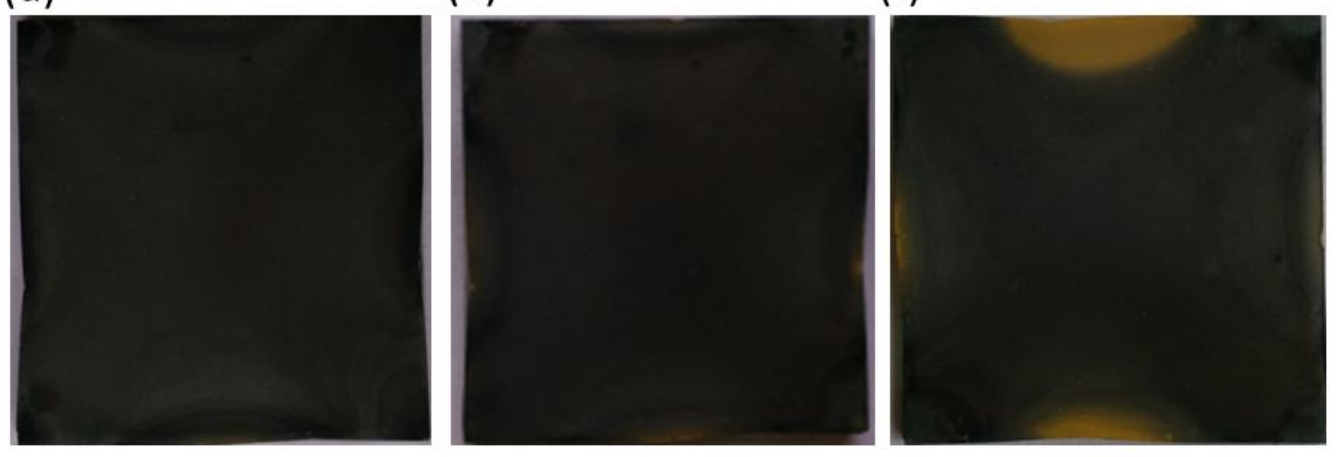




\section{Figure 5}

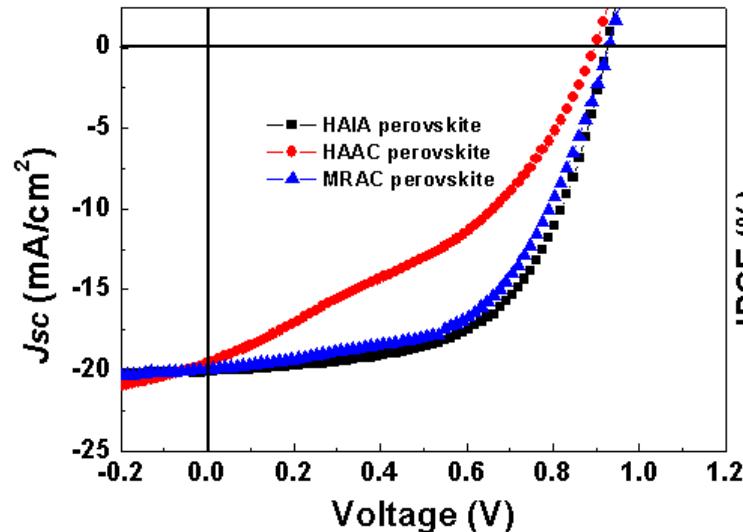

(a)

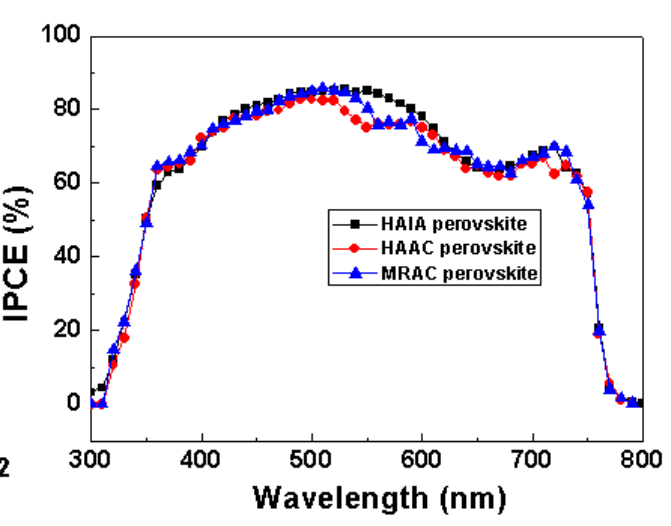

(b) 
Figure 6

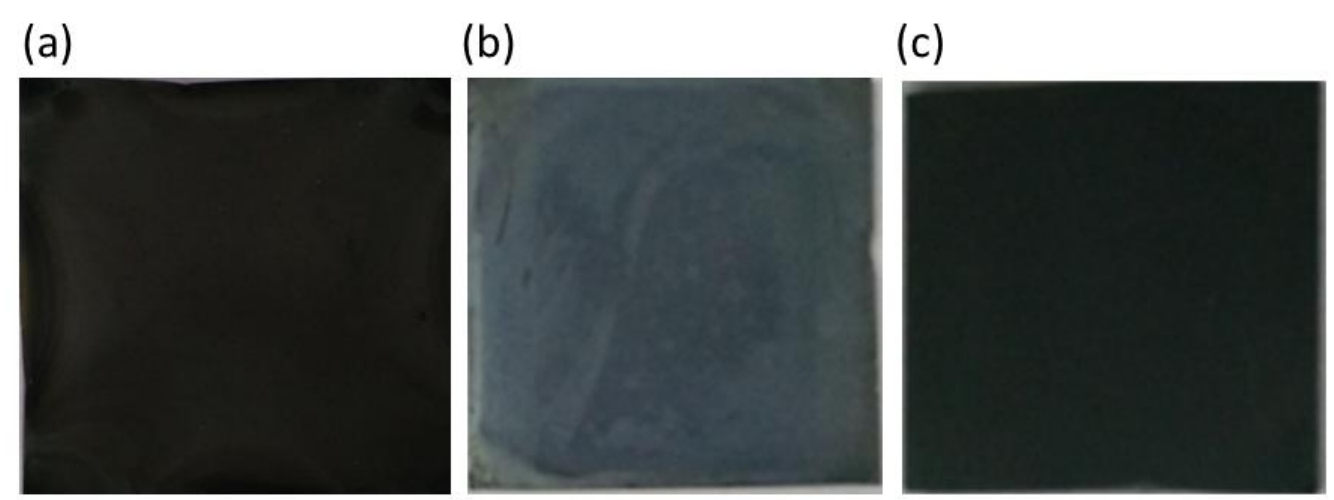

(d)

(e)

(f)
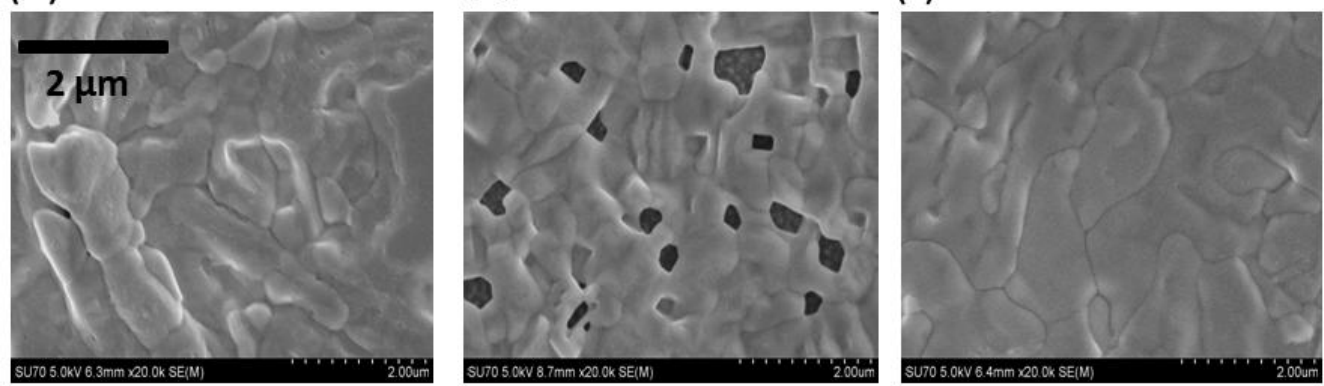
Figure 7

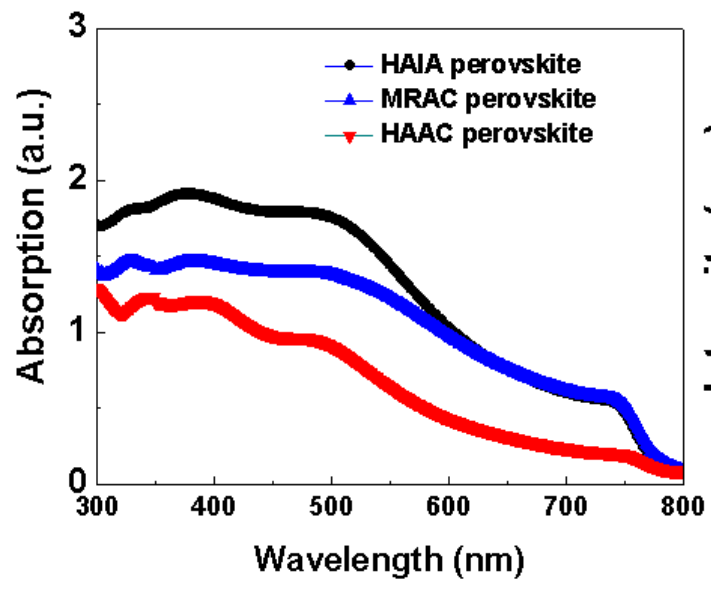

(a)

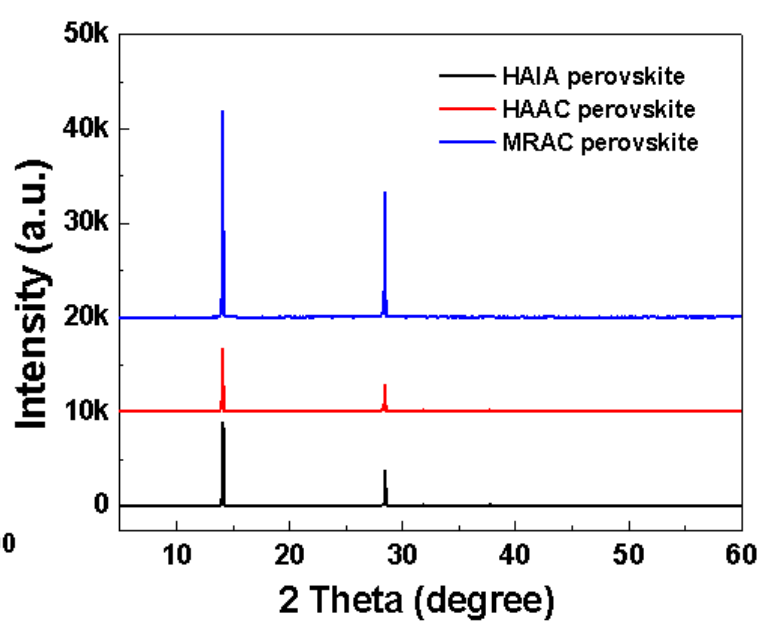

(b) 
Table 1

\begin{tabular}{cccccc}
\hline $\begin{array}{c}\text { Power } \\
(\mathrm{W})\end{array}$ & $\begin{array}{c}\text { Time } \\
(\mathrm{min})\end{array}$ & $\begin{array}{c}J_{s c} \\
\left(\mathrm{mAcm}^{-2}\right)\end{array}$ & $\begin{array}{c}V_{o c} \\
(\mathrm{~V})\end{array}$ & FF & $\begin{array}{c}\text { PCE } \\
(\%)\end{array}$ \\
\hline 160 & 10 & 18.74 & 0.85 & $49.5 \%$ & $7.89( \pm 0.53)$ \\
320 & 5 & 20.51 & 0.90 & $48.3 \%$ & $8.93( \pm 0.61)$ \\
480 & 3 & 17.64 & 0.89 & $58.6 \%$ & $9.20( \pm 0.95)$ \\
640 & 2.5 & 18.79 & 0.89 & $47.0 \%$ & $7.87( \pm 1.05)$ \\
\hline
\end{tabular}


Graphical Abstarct
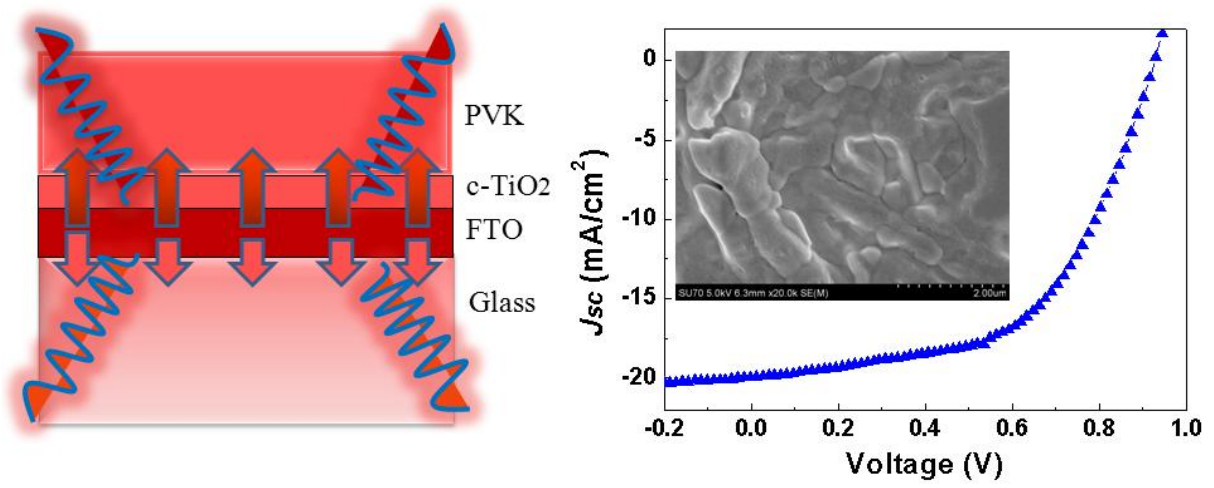